\title{
A New Source of Resistance to Tapesia yallundae Associated with a Homoeologous Group 4 Chromosome in Thinopyrum ponticum
}

\author{
H. J. Li, M. Arterburn, S. S. Jones, and T. D. Murray
}

First author: Department of Plant Pathology; second and third authors: Department of Crop and Soil Sciences; and fourth author: Department of Plant Pathology, Washington State University, Pullman 99164. Accepted for publication 29 April 2004.

\begin{abstract}
Li, H. J., Arterburn, M., Jones, S. S., and Murray, T. D. 2004. A new source of resistance to Tapesia yallundae associated with a homoeologous group 4 chromosome in Thinopyrum ponticum. Phytopathology 94:932937.

Wheat (Thinopyrum ponticum line SS767; PI 611939) with 42 chromosomes previously was identified as a new source of eyespot resistance. Individual plants of SS767 were tested for reaction to Tapesia yallundae, the major pathogen of eyespot in the Pacific Northwest region of the United States. Resistance of this line was similar to the resistant winter wheat cv. Madsen (carrying gene Pch1 for eyespot resistance). Polymerase chain reaction analysis with primers specific for the $\mathrm{J}$ or $\mathrm{E}$ genomes

line in which wheat chromosome 4D is replaced by a homoeologous group 4 chromosome of Thinopyrum ponticum. Genomic in situ hybridization using St genomic DNA from Pseudoroegneria strigosa as a probe, which can differentiate chromosomes from different genomes of Thinopyrum, indicated that this chromosome belongs to the $\mathrm{J}$ genome. Molecular analysis of an $\mathrm{F}_{2}$ population segregating for chromosome $4 \mathrm{~J}$ and resistance to eyespot confirmed that eyespot resistance in line SS767 is associated with chromosome $4 \mathrm{~J}$ of Thinopyrum ponticum. This is the first report of genetic control of resistance to eyespot derived from Thinopyrum ponticum. This source of resistance provides a new opportunity to improve wheat resistance to eyespot by adding to the diversity of resistance sources available.
\end{abstract} revealed that SS767 contains Thinopyrum chromatin. Cytological and Cbanding analyses demonstrated that SS767 is a chromosome substitution
Additional keywords: blue kernel color, Pseudocercosporella.
Eyespot, caused by Tapesia yallundae Wallwork \& Spooner (anamorph: Pseudocercosporella herpotrichoides (Fron) Deighton), is one of the major yield-limiting diseases of winter wheat (Triticum aestivum L.) in the Pacific Northwest (PNW) region of the United States (29). This soilborne fungal disease also can be a serious problem for wheat production in other parts of the world with cool and wet winters, such as northwestern Europe, Australia, and New Zealand (34). Although fungicides can be effective in reducing yield losses from the disease, the occurrence of fungicide-resistant isolates of the pathogen has increased the need for host resistance to limit eyespot epidemics $(19,29)$.

At present, two genes are used in commercial wheat cultivars resistant to eyespot. The gene $P$ chl, which was introduced from Triticum ventricosum Ces. into breeding line VPM-1, is located on chromosome 7DL $(9,27)$. This gene often is used by breeders because it is generally effective. However, the resistance to eyespot conferred by $P$ chl can be less effective in some backgrounds (24). The French wheat cv. Cappelle Desprez carries gene Pch2 of unknown origin on chromosome 7AL, which is less effective than Pchl in controlling eyespot. This cultivar is reported to contain other minor resistance genes, making it hard to recover its full resistance (21). The effectiveness of these two genes is insufficient to preclude the application of fungicides when eyespot is severe $(16,17)$. Despite these limitations, Pch1 and Pch2 are the major sources of resistance against eyespot in many breeding programs because other resistance genes are not available to breeders $(1-3,16,17)$.

Corresponding author: T. D. Murray; E-mail address: tim_murray@wsu.edu

Publication no. P-2004-0714-01R

(c) 2004 The American Phytopathological Society
Murray et al. (30) determined that chromosome 4V in Dasypyrum villosum L. Candargy (syn. Haynaldia villosa L.), a distant relative of wheat, is associated with resistance to eyespot. Yildirim et al. (35) further mapped a single dominant gene, Pch3, for eyespot resistance to chromosome 4VL. This resistance gene needs to be incorporated into more adapted wheat genotypes before it can be used easily in breeding programs. There is a need to identify more resistance genes to reduce potential genetic vulnerability due to the limited number of resistance genes against this pathogen.

Resistance is uncommon in bread wheat; therefore, wild grasses closely or distantly related to wheat have been evaluated for resistance to eyespot $(4,7,10,13,15,26,36,37)$. Eyespot resistance was found in several diploid species, including Triticum tauschii (Coss.) Schmal. (syn. Aegilops squarrosa L.) (36), Triticum monococcum L. subsp. monococcum (4), and D. villosum (37). Eyespot resistance also was discovered in some tetraploid Triticum spp., including Triticum dicoccoides Körn., Triticum durum Desf., and Triticum turanicum Jakubz. (13). Resistant wheat lines also have been developed from wheat-A. kotschyi Boiss crosses (32).

The tall wheatgrass Thinopyrum ponticum (Podp.) Liu \& Wang (syn. Agropyron elongatum (Host) P. Beauv. and Elytrigia elongata (Host) Beauv.) has provided resistance genes for leaf rust (caused by Puccinia triticina Eriks.) (20,31), stem rust ( $P$. graminis Pers. f. sp. tritici Eriks. \& Henn.) (28), Wheat streak mosaic virus (WSMV) and its vector the wheat curl mite (WCM), Aceria tosichella Keifer (6), Barley yellow dwarf virus (BYDV) $(12,39)$, Cephalosporium stripe (Cephalosporium gramineum Nis. \& Ika.) (5), and common root rot (Cochliobolus sativus (Ito \& Kuribayashi) Drechs. ex Dastur) (23). Allan et al. (3) registered a soft white winter wheat germ plasm line WA7437 (PI 561033) with tolerance to eyespot, which had Thinopyrum ponticum in its pedigree. Resistance to eyespot recently was identified in Thino- 
pyrum ponticum and wheat-Thinopyrum ponticum derivatives (7); however, there is no specific information on the genetic control of eyespot resistance in Thinopyrum ponticum, which is important for wheat improvement.

Cox et al. (7) also identified wheat-Thinopyrum ponticum line SS767 (PI 611939) with blue kernel color as resistant to eyespot. The occurrence of blue kernel color in wheat is caused by anthocyanin pigments in the aleurone layer and is controlled by a single gene, $\mathrm{Bal}$, located on a homoeologous group 4 chromosome of Thinopyrum ponticum, which has been introduced into wheat (18). Although blue kernel color is attractive for genetic studies, few genes of agronomic importance or disease resistance show linkage to this trait (38). The purpose of this study was to specifically characterize resistance to Tapesia yallundae in SS767 and to determine the association of the alien chromosome with eyespot resistance in this line.

\section{MATERIALS AND METHODS}

Plant materials. Line SS767 is one of the W. J. Sando selections from the cross Triticum vulgare Sac75//Sol/Agropyron elongatum//Leapland/Meister amphiploid wheat/rye Br215. Because variation in kernel color was observed, 108 individual plants of line SS767 were analyzed for reaction to Tapesia yallundae. The susceptible spring wheat cv. Chinese Spring (CS) and winter wheat cvs. Eltan and Hill 81 were used as controls for determining reaction to eyespot. The resistant winter wheat cv. Madsen, which contains Pchl and is adapted to the PNW (1), and a resistant wheat-Thinopyrum ponticum partial amphiploid, AT3425 $(2 n=56)(7)$, were used in eyespot tests as resistant controls. An accession of Thinopyrum ponticum (JJJJ ${ }^{\mathrm{s}} \mathbf{J}^{\mathrm{s}}$ genome, $2 n=70)$ (PI 206624), Thinopyrum intermedium (Host.) Barkworth \& D. R. Dewey (StJJ's genome, $2 n=42)($ PI 264770), T. elongatum (syn. Lophopyrum elongatum, E genome, $2 n=14$ ) (PI 547326), and Pseudoroegneria strigosa (M. Bieb) A. Löve (St genome, $2 n=14$ ) (PI 499493) were used as controls in detection of Thinopyrum ponticum chromatin by polymerase chain reaction (PCR). The controls for molecular analysis also included a Chinese Spring-Thinopyrum elongatum 4E chromosome addition line, CS + 4E (TA3667); a disomic chromosome substitution line, DS 4E(4D); and a wheat-Thinopyrum bessarabicum (J genome, $2 n=14)$ addition line PC261 $(\mathrm{CS}+4 \mathrm{~J}) . \mathrm{F}_{1}$ and $\mathrm{F}_{2}$ plants from a cross between SS767 and Eltan also were tested for reaction to Tapesia yallundae. The $\mathrm{F}_{1}$ plants from crosses of SS767 $\times$ Eltan and SS767 $\times$ DS 4E(4D) were used to determine chromosome composition of SS767 by analyzing chromosome paring during meiosis.

Evaluation for reaction to eyespot. The controls were arranged in a complete block design with five replicates composed of two plants each. Seed of each line, together with individual plants of SS767, and $F_{1}$ and $F_{2}$ plants of SS767 $\times$ Eltan, were imbibed on filter paper in petri dishes moistened with sterile distilled water at $4^{\circ} \mathrm{C}$ for 4 days before seeding. A mixture of conidia containing approximately equal numbers of $\beta$-glucuronidase (GUS)-transformed Tapesia yallundae strains (tph8934-561, tph8934-5-62, tph8934-5-68, and tph8934-5-70) from the PNW was used to inoculate seedlings at the two-leaf stage $(7,8)$. Eight weeks following inoculation, plants were rated visually for disease severity on a 1-to- 4 scale, where $1=$ no lesion, $2=$ a lesion on the first sheath or tiny lesions on the first or second sheath (hypersensitive reaction), $3=$ a lesion on the first and second sheath, and $4=$ a lesion covering over the entire first sheath and two-thirds of the second sheaths. Individual plants with visual rating scores of 1 or 2 were considered resistant to Tapesia yallundae, whereas plants with rating scores of 3 or 4 were regarded as susceptible. Individual stems $3 \mathrm{~cm}$ long were excised from the base of the main tiller of each plant, wrapped in paper towels, and stored at $-20^{\circ} \mathrm{C}$ until analysis of GUS activity.
GUS analysis. The sampled stems were ground individually in $2.5 \mathrm{ml}$ of extraction buffer $(50 \mathrm{mM} \mathrm{NaHPO}$, pH 7.0, $5 \mathrm{mM}$ dithiothreitol, $10 \mathrm{mM} \mathrm{Na} \mathrm{EDTA}_{2} 0.1 \%$ sodium lauryl sarcosine, and $0.1 \%$ Triton-100) and GUS activity was detected by conversion of 4-methylumbelliferyl $\beta$-D-glucoside (MUG) to 4methylumbelliferone by GUS as described previously $(7,8)$. GUS scores were log-transformed before conducting analysis of variance. Fisher's least significant difference $(P=0.05)$ generated by SAS (SAS Institute, Raleigh, NC) was used to differentiate GUS scores of individual plants and means of controls (25). Plants or mean scores of a cultivar with a GUS score less than or not significantly greater than that of the resistant control Madsen were regarded as resistant to Tapesia yallundae; otherwise, they were considered as susceptible.

Cytological analyses. The genomic constitution of SS767 was characterized by $\mathrm{C}$-banding and genomic in situ hybridization (GISH). Mitotic chromosomes were viewed by squashing root tips that were fixed in 95\% ethanol-glacial acetic acid (3:1) after pretreatment with ice water at $4^{\circ} \mathrm{C}$ for $24 \mathrm{~h}$. To determine meiotic chromosome pairing patterns, young spikes were immersed in 95\% ethanol-chloroform-glacial acetic acid (6:3:1) for 2 weeks, immersed in $95 \%$ ethanol for $5 \mathrm{~min}$, then stored at $4{ }^{\circ} \mathrm{C}$ in $70 \%$ ethanol. Anthers at meiotic metaphase I stage were squashed in $1 \%$ acetocarmine to observe chromosome pairing. All slides were stored at $-80^{\circ} \mathrm{C}$ until they were used for C-banding or GISH analysis (22).

Mitotic chromosome preparations were stored in $95 \%$ ethanol overnight after removing the cover slips with a razor blade. Cbanding analysis was carried out following a method described by Gill et al. (14). Individual wheat chromosomes were differentiated according to the nomenclature of standard C-banding patterns of wheat chromosomes (14). Total genomic DNA of $P$. strigosa and rye (Secale cereale L., R genome, $2 n=14$ ) cv. Merced were labeled separately as probes with biotin-14-dATP via nick translation (BioNick Labeling System; Invitrogen Life Technologies, Carlsbad, CA). Genomic DNA of Chinese Spring was sheared to serve as blocking DNA. A previously published protocol (6) was followed to carry out GISH analysis on chromosome preparations. The hybridization signals were detected with fluorescein isothiocyanate (FITC)-avidin DN and biotinylated goat anti-avidin D (Vector Laboratories, Inc., Burlingame, CA). The wheat chromosomes were counterstained red with propidium iodide solution. The slides were mounted with a thin layer of antifade solution and the yellow-green FITC-labeled signals were captured using a Zeiss fluorescent microscope (Carl Zeiss, Oberkochen, Germany) with a digital camera (Diagnostic Instruments Inc., Sterling Heights, MI).

PCR. The presence of Thinopyrum ponticum chromatin in individual plants of SS767, and $F_{1}$ and $F_{2}$ plants of the cross SS767 $\times$ Eltan, was confirmed by PCR using primers $2 \mathrm{P} 1$ and $2 \mathrm{P} 2$, which are specific for a repetitive DNA sequence from Thinopyrum elongatum, pLeUCD2 (33). The reaction mixture was composed of $2.5 \mu \mathrm{l}$ of $10 \times$ buffer, $3.0 \mu \mathrm{l}$ of $\mathrm{MgCl}_{2}(50 \mathrm{mM})$, $2.0 \mu \mathrm{l}$ of dNTP (10 mM each), $100 \mathrm{ng}$ of primer $2 \mathrm{P} 1{\left(5^{\prime}\right.}^{\prime}$ ACAATCTGAAAATCTGGACA3') and primer 2P2 (5' TCATATTGAGACTCCTATAA3') each, $200 \mathrm{ng}$ of sample DNA, and 2 units of Taq DNA polymerase. The amplification was carried out with a GeneAmp9600 thermocycler (Perkin-Elmer, Norwalk, CT) programmed at $94^{\circ} \mathrm{C}$ for $3 \mathrm{~min}$; followed by 35 cycles of $94^{\circ} \mathrm{C}$ for $1 \mathrm{~min}, 47$ to $52^{\circ} \mathrm{C}$ ramp annealing for $45 \mathrm{~s}$, and $72^{\circ} \mathrm{C}$ for $1 \mathrm{~min}$; and final extension at $72^{\circ} \mathrm{C}$ for $5 \mathrm{~min}$. The amplified products were separated on a $1.5 \%$ agarose gel.

\section{RESULTS}

Reaction to Tapesia yallundae infection. In all, 108 plants of SS767 were inoculated with GUS-transformed Tapesia yallundae. No lesions or hypersensitive reactions with visual ratings of 1 or 
2 developed on plants of SS767 or the resistant wheat-Thinopyrum ponticum partial amphiploid AT3425, which were similar to Madsen. All plants of the wheat-Thinopyrum elongatum chromosome addition line $\mathrm{CS}+4 \mathrm{E}$ and the chromosome substitution line DS 4E(4D), and the susceptible controls Chinese Spring, Hill 81, and Eltan exhibited obvious lesions on the basal part of the main tiller, resulting in visual ratings of 3 or 4 (data not shown). Hypersensitive reactions were also present on all eight $F_{1}$ plants of the cross SS767 $\times$ Eltan. A total of $193 \mathrm{~F}_{2}$ plants segregated for visual ratings ranging from 1 to 4 (data not shown).

GUS analysis confirmed the visual assessments for reaction to Tapesia yallundae. The frequency distribution for GUS scores of individual plants of SS767 and controls, when log-transformed based on Madsen, is illustrated in Figure 1. GUS scores ranged from 0.3 to 1.2 for plants of SS767, with a mean GUS score of $0.7 \pm 0.2$, which was not significantly different from the resistant controls Madsen and AT3425 (Fig. 1). The susceptible cvs. CS, Hill 81, and Eltan had GUS values ranging from 1.8 to 2.0, which were significantly greater than that of Madsen and AT3425 (Fig. 1). The GUS values for 12 plants of $C S+4 E(1.7 \pm 0.5)$ and 22 plants of DS 4E(4D) $(2.0 \pm 0.6)$ indicated that these two lines are susceptible to eyespot.

GUS scores, using SS767 as the resistant parent, for eight $F_{1}$ plants derived from the cross SS767 $\times$ Eltan ranged from 1.0 to 1.5 with a mean of $1.2 \pm 0.2$; the phenotypes of these $F_{1}$ plants were either resistant to Tapesia yallundae as SS767 or intermediate in resistance between SS767 and Eltan. Visual disease ratings were consistent with GUS scores. GUS scores for $193 \mathrm{~F}_{2}$ plants from the same cross ranged from 0.5 to 2.6 with a mean of $1.4 \pm 0.4$. Due to the unpredictability of monosome transmission, $\mathrm{F}_{2}$ segregation ratios were not determined.

Cytological analysis. Chromosome number of SS767 was determined on 30 plants and all had 42 chromosomes. Meiotic analysis revealed 21 bivalents in the majority of meiotic metaphase I cells in SS767. When SS767 was crossed with cv. Eltan, the $F_{1}$ plants produced 20 bivalents and 2 univalents in most (95\%) meiotic metaphase I cells, indicating that SS767 is a chromosome substitution line (Table 1). Meiotic pairing analysis also revealed that the alien chromosome of SS767 did not pair with chromosome 4E originating from Thinopyrum elongatum, as indicated by 20 bivalents and 2 univalents in the SS767 $\times$ DS 4E(4D) cross. This result indicated that SS767 had the same chromosome composition as the wheat-Thinopyrum elongatum chromosome substitution line DS 4E(4D), except for the alien chromosomes (Table 1).

One pair of chromosomes that originated from Thinopyrum ponticum was detected in SS767 using St genomic DNA from $P$. strigosa as a probe, which can differentiate chromosomes belonging to the different genomes of Thinopyrum, and ABD genomic DNA from Chinese Spring as a blocker. The yellowgreen FITC-hybridization signals were distributed evenly along the complete length of the labeled chromosome, indicating that it belongs to the $\mathrm{J}$ genome. The remaining 40 chromosomes were counterstained red by propidium iodide, demonstrating that they were wheat chromosomes (Fig. 2A). GISH analysis of meiotic chromosomes detected 20 wheat bivalents and a Thinopyrum

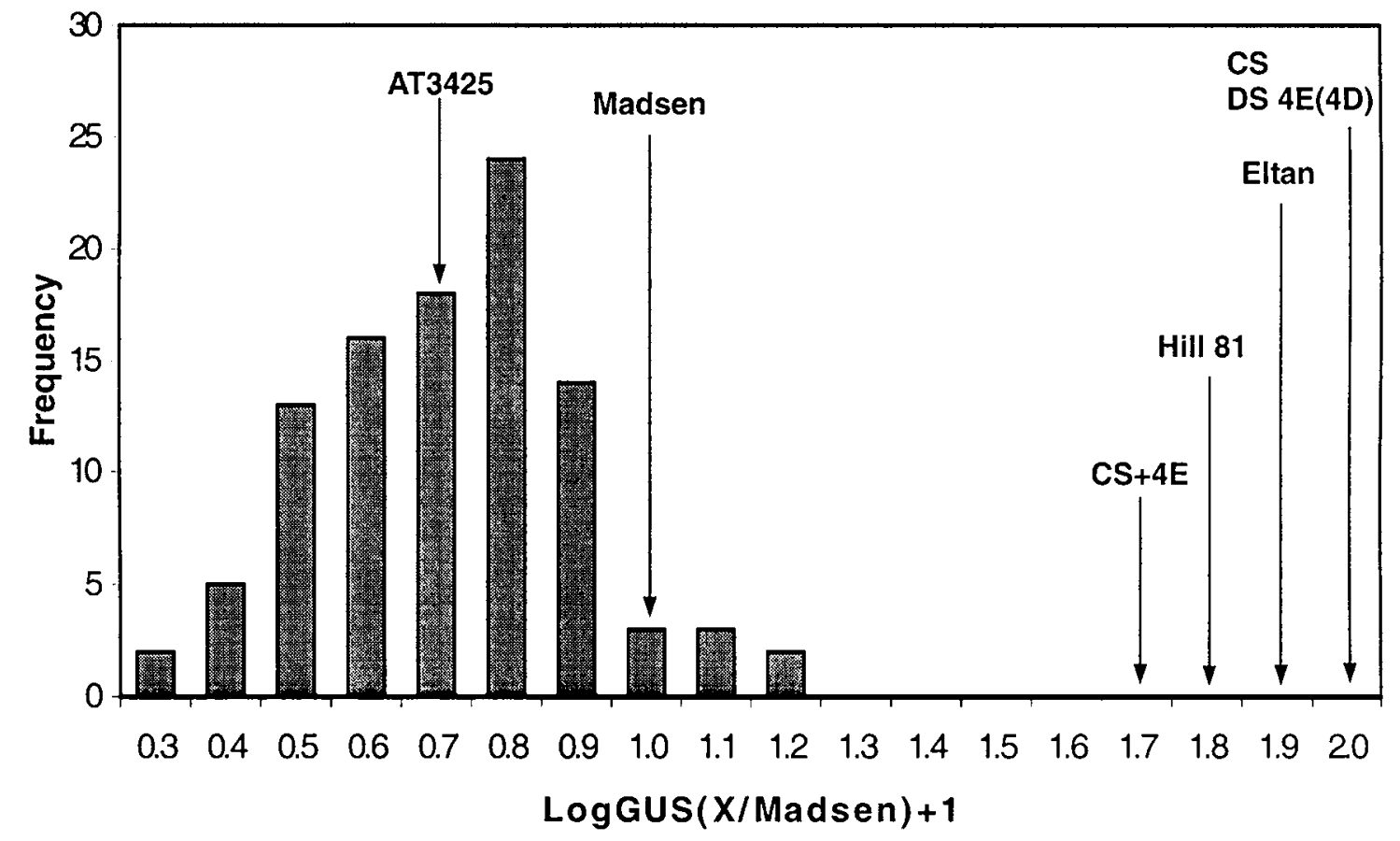

Fig. 1. Reaction of individual plants of SS767 and controls to inoculation with $\beta$-glucuronidase (GUS)-transformed Tapesia yallundae. The GUS scores are presented as the ratio of a plant to the resistant control Madsen plus one (i.e., $\log 10$ (X/Madsen) + 1). The protected least significant difference (LSD) (i.e., LSD = $0.2, P=0.05$ ) was used to differentiate the GUS scores of individual plants in SS767 and means of the controls. Plants or entries are considered resistant when their GUS scores are not significantly greater than that of Madsen (i.e., GUS $=1$ ).

TABLE 1. Chromosome pairing configuration of SS767 and $\mathrm{F}_{1}$ crosses at meiotic metaphase I

\begin{tabular}{lcccc}
\hline & \multicolumn{4}{c}{ Chromosome pairing configurations $^{\mathrm{a}}$} \\
\cline { 2 - 5 } Line or crosses & No. of cells observed & $21 \mathrm{II}$ & 20 II + 2 I & \\
\hline SS767 & 260 & $252(96.9 \%)$ & $8(3.1 \%)$ & 19 II + 4 I \\
SS767 $\times$ Eltan & 120 & $6(5.0 \%)$ & $114(95.0 \%)$ & 0 \\
SS767 $\times$ DS 4E(4D) & 100 & $7(7.0 \%)$ & $90(90.0 \%)$ & 0 \\
\hline
\end{tabular}

${ }^{\text {a }} \mathrm{I}=$ univalent, $\mathrm{II}=$ bivalent. Numbers in parentheses are the percentage of the total cells observed. 
bivalent in this wheat-Thinopyrum ponticum line, which agrees with GISH analysis of mitotic chromosomes (data not shown). Cbanding revealed that the 4D chromosome of SS767 was replaced by a chromosome exhibiting terminal bands at both ends of the chromosome and interstitial bands on the short arm or near the centromeric region (Fig. 2B). C-banding patterns of all chromosomes in SS767 did not show terminal heterochromatic bands typically present in rye chromosomes (Fig. 2B). GISH using rye genomic DNA as a probe confirmed that no chromatin originated from rye in SS767 (data not shown).

PCR amplification. A PCR product $277 \mathrm{bp}$ in length was amplified using genome-specific primers in all plants of SS767 tested for reaction to eyespot, indicating that they all contained Thinopyrum chromatin. The band also was present in $\mathrm{CS}+4 \mathrm{E}$, DS 4E(4D), PC261 (CS + 4J), AT3425, Thinopyrum ponticum, and Thinopyrum elongatum and was absent in CS, Madsen, and Hill 81 (Fig. 3).

Because chromosome $4 \mathrm{~J}$ was in a monosomic state in the $\mathrm{F}_{1}$ plants, $\mathrm{F}_{2}$ data are unpredictable in terms of chromosome transmission. Therefore, segregation analysis was performed on known resistant and susceptible lines. Based on visual ratings and GUS scores, 16 resistant and 16 susceptible $F_{2}$ plants from the cross SS767 $\times$ Eltan were analyzed using the genome-specific primers described above. The diagnostic band was amplified from all resistant plants, but was not detected in any of the susceptible plants (Fig. 4), indicating that only the resistant plants contained Thinopyrum chromatin.

\section{DISCUSSION}

The wheatgrasses Thinopyrum ponticum and Thinopyrum intermedium recently were identified as potential new sources of eyespot resistance for wheat (7). In this study, individual plants of SS767, which is derived from a wheat-Thinopyrum ponticum cross, were tested for reaction to Tapesia yallundae. All of the plants exhibited eyespot resistance comparable to or better than the resistant wheat-Thinopyrum ponticum partial amphiploid AT3425 and the resistant winter wheat cv. Madsen. The eyespot resistance of SS767 was effective in $F_{1}$ plants from the cross SS767 $\times$ susceptible wheat cv. Eltan, and eyespot-resistant plants can be selected from the segregating populations based on GUS analysis. This suggests that SS767 is useful in breeding programs aimed at improving wheat resistance to Tapesia yallundae. Although genes Pch1 and Pch2 are used widely in many programs to develop eyespot-resistant wheat cultivars $(1-3,11,17)$, each of them alone provides inadequate protection from eyespot epidemics under favorable environments. The newly characterized eyespot-resistant wheat-Thinopyrum ponticum line SS767 thus offers a new source of resistance to the disease. Introgression of this resistance to wheat cultivars adapted to the PNW is in progress.

Understanding the genomic origin of eyespot resistance in SS767 will facilitate its use in wheat improvement programs. Meiotic analysis indicates that SS767 is a chromosome substitution line. GISH, using a probe from St genomic DNA of P. strigosa, confirmed the presence of a pair of Thinopyrum ponticum chromosomes in SS767 (Fig. 2A). C-banding analysis demonstrates that this alien chromosome has unique heterochromatic bands at both terminal regions which are uncommon in any wheat chromosome (Fig. 2B). C-banding also demonstrated that wheat chromosome 4D was replaced. Although SS767 contains rye in its pedigree, rye chromatin was not detected by GISH and C-banding analyses, indicating that the eyespot resistance in SS767 was not derived from rye. Using primers specific for Thinopyrum genomes, PCR demonstrated that all eyespot-resistant plants of the parent SS767 and all 16 resistant $F_{2}$ plants from the SS767 × Eltan cross carried Thinopyrum chromatin, whereas the susceptible control plants and 16 susceptible $F_{2}$ plants ana- lyzed did not possess chromatin from a Thinopyrum sp., which indicates that the eyespot resistance of SS767 is associated with the chromosome derived from Thinopyrum ponticum.

Line SS767 has blue kernels resulting from blue pigmentation in the aleurone layer. The blue kernel trait of wheat arising from Thinopyrum ponticum is associated with a single dominant gene on a chromosome belonging to the homoeologous group 4 (18). Therefore, eyespot resistance of Thinopyrum ponticum, as expressed in the wheat-Thinopyrum ponticum chromosome substitution line SS767, is associated with genes located on the same homoeologous group 4 chromosome on which the gene for blue pigmentation is located. Eyespot-resistance genes Pch1 and Pch2 are conferred by homoeologous group 7 chromosomes $(9,21)$. Gene Pch 3 from the more distantly related species D. villosum
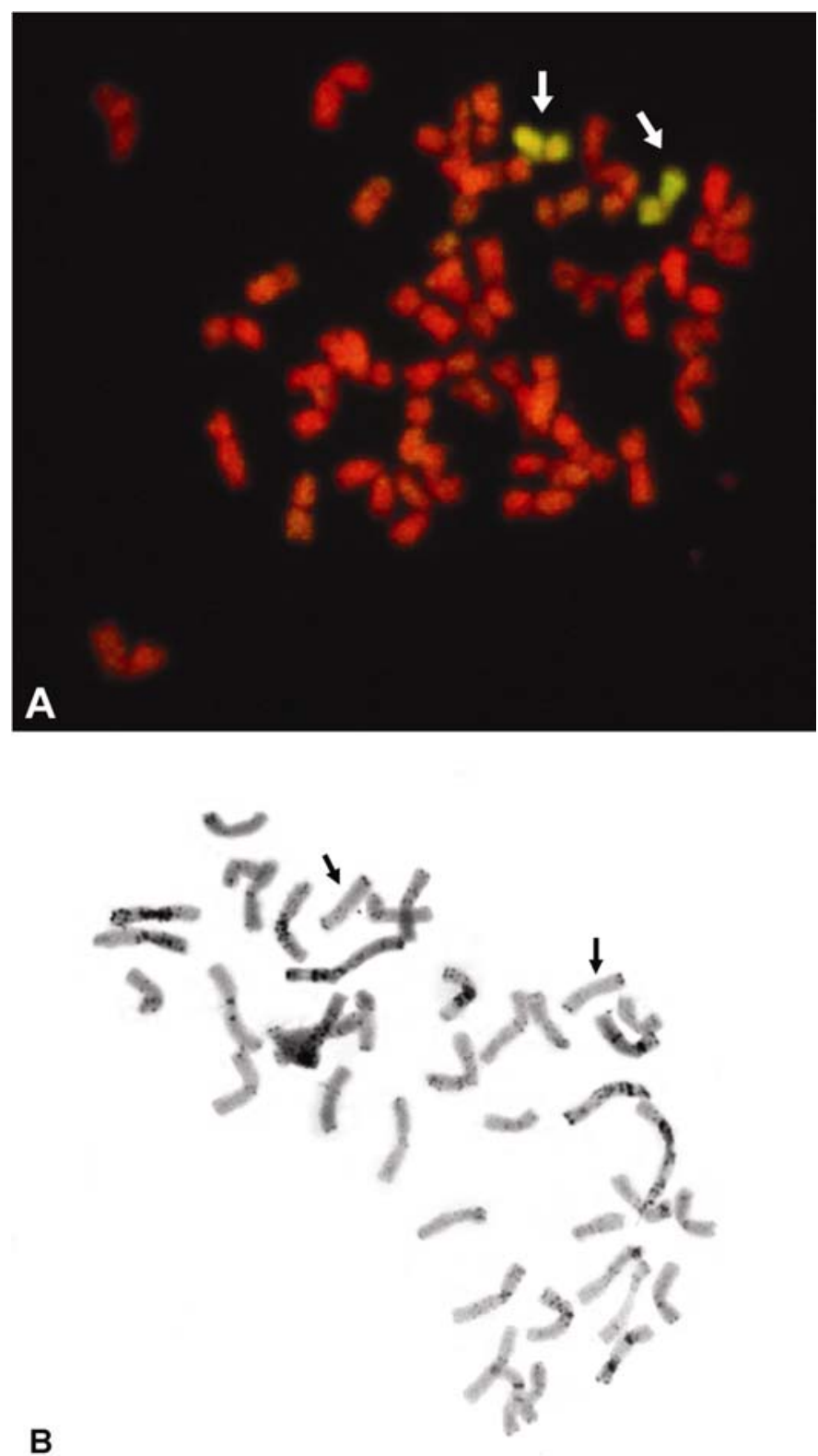

Fig. 2. Genomic in situ hybridization (GISH) and C-banding analyses of SS767. A, GISH analysis using St genomic DNA from Pseudoroegneria strigosa as a probe in the presence of ABD genomic DNA as a blocker detects a pair of J genome chromosomes in line SS767, as indicated by their evenly distributed fluorescent signal along the entire length of the chromosome (arrows). B, C-banding analysis showing wheat chromosomes 4D replaced by Thinopyrum ponticum chromosomes that display heterochromatic bands at both terminal regions of the chromosomes and interstitial bands on the short arm or near the centromeric region (arrows). 


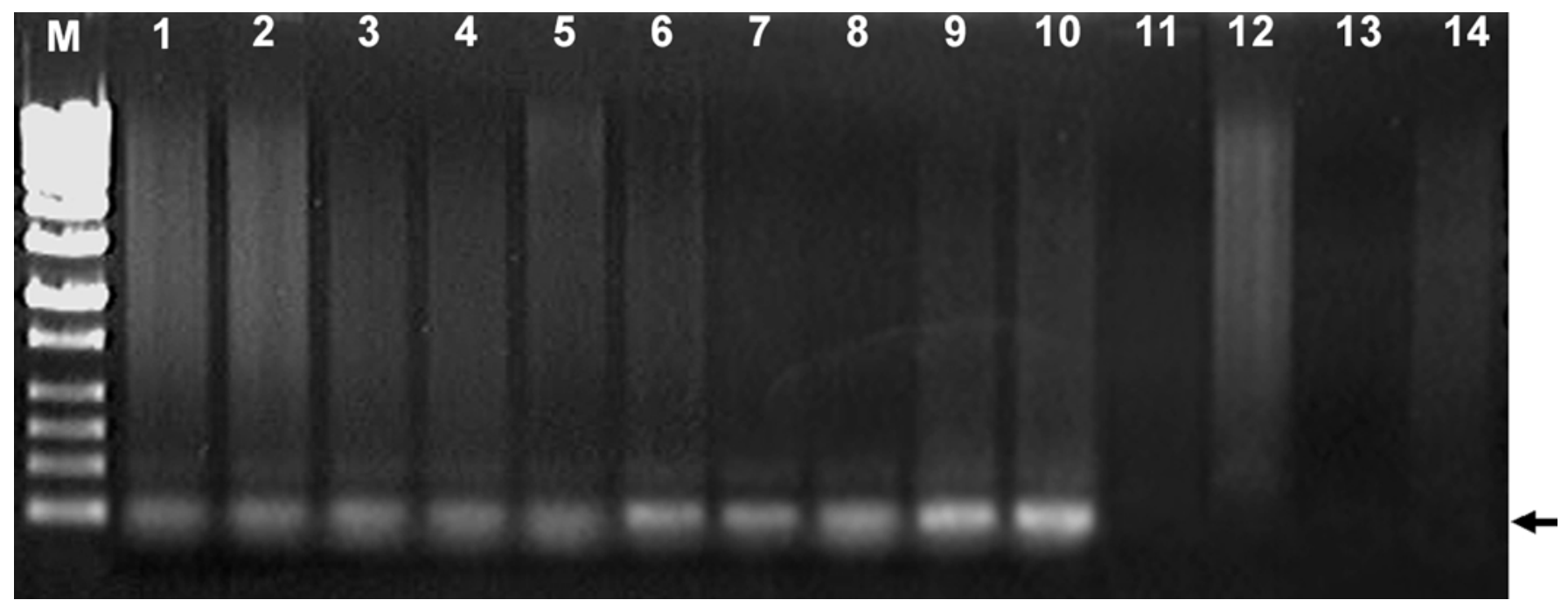

Fig. 3. Profile of polymerase chain reaction products amplified with primers $2 \mathrm{P} 1$ and $2 \mathrm{P} 2$, which are specific for a repetitive DNA sequence, pLeUCD2, originating from Thinopyrum elongatum, in the genus Thinopyrum. Lane $\mathrm{M}=1 \mathrm{~kb}$ DNA ladder, lane $1=\mathrm{CS}+4 \mathrm{E}$, lane $2=\mathrm{DS} 4 \mathrm{E}(4 \mathrm{D})$, lane $3=\mathrm{AT} 3425$, lane $4=$ SS767, lane $5=\mathrm{SS767}$, lane $6=$ wheat $+4 \mathrm{~J}$, lane $7=$ Thinopyrum elongatum, lane $8=$ Pseudoroegneria strigosa, lane $9=$ Thinopyrum intermedium, lane $10=$ Thinopyrum ponticum, lane $11=\mathrm{CS}$, lane $12=$ Madsen, lane $13=$ Eltan, and lane $14=$ Hill 81 . Arrow indicates the diagnostic band $277 \mathrm{bp}$ in length

\section{M1 23 R S R SR S R S R S R S R SR SR SR SR SR SR SR SR SR S}

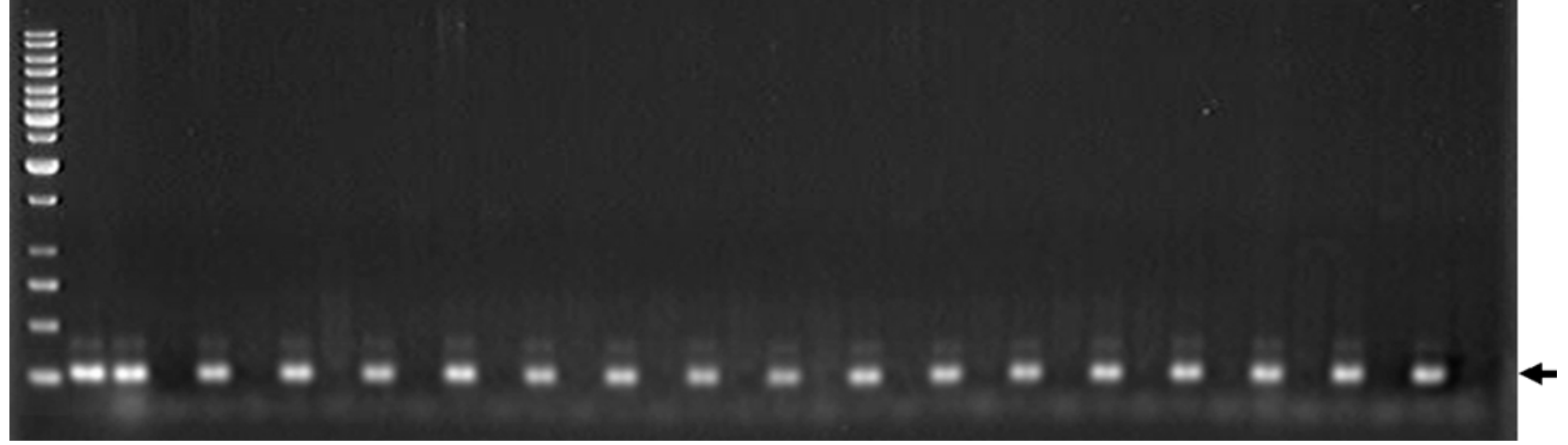

Fig. 4. Polymerase chain reaction products amplified by the genome-specific primers $2 \mathrm{P} 1$ and $2 \mathrm{P} 2$ from $\mathrm{F}_{2}$ plants derived from the cross $\mathrm{SS} 767 \times$ Eltan showing the diagnostic band of $277 \mathrm{bp}$ (arrow) present in all plants resistant $(\mathrm{R})$ to eyespot but absent in all plants susceptible (S) to eyespot. Lane $\mathrm{M}=1$-kb DNA ladder, lane $1=$ Thinopyrum ponticum, lane $2=\mathrm{SS} 767$, and lane $3=$ Eltan.

resides on chromosome $4 \mathrm{VL}(30,35)$. The chromosome arm location of the eyespot resistance gene or genes in SS767 remains to be determined.

Tolerance to eyespot has been reported in a soft white wheat germ plasm line, which is derived from a wheat-Thinopyrum ponticum cross (3). Variable reaction of another wheat-Thinopyrum ponticum line, SS241 (PI 611900), also from W. J. Sando selections, to Tapesia yallundae was observed (7). This line contains a pair of $\mathbf{J}^{\mathrm{s}}$ translocation chromosomes and one or two $\mathrm{J}^{\mathrm{s}}$ telocentric chromosomes from Thinopyrum ponticum (unpublished data). Together, these suggest that other chromosomes of Thinopyrum ponticum might have additional genes for eyespot resistance in addition to the gene or genes carried by the Thinopyrum ponticum chromosome in SS767.

In conclusion, resistance to Tapesia yallundae in line SS767 is controlled by genes located on chromosome $4 \mathrm{~J}$ derived from Thinopyrum ponticum. This $\mathrm{J}$ genome chromosome also is responsible for blue pigmentation of wheat arising from Thinopyrum ponticum. This is the first report of eyespot resistance conferred by a $\mathrm{J}$ genome chromosome of Thinopyrum ponticum.
The wheat-Thinopyrum ponticum 4J(4D) chromosome substitution line SS767 provides a new source of eyespot resistance, which may be useful for wheat improvement.

\section{ACKNOWLEDGMENTS}

Plant Pathology New Series 0371, College of Agriculture and Home Economics Agricultural Research Center Project 0670. The financial support of the Washington State Wheat Commission is gratefully acknowledged. We thank L. Pritchett for technical assistance.

\section{LITERATURE CITED}

1. Allan, R. E., Peterson, C. J., Jr., Rubenthaler, G. L., Line, R. F., and Roberts, D. E. 1989. Registration of 'Madsen' wheat. Crop Sci. 29:15751576.

2. Allan, R. E., Peterson, C. J., Jr., Rubenthaler, G. L., Line, R. F., and Roberts, D. E. 1990. Registration of 'Hyak' wheat. Crop Sci. 30:234.

3. Allan, R. E., Rubenthaler, G. L., Mirus, C. F., and Line, R. F. 1993. Registration of three soft white winter wheat germplasm lines resistant or tolerant to strawbreaker foot rot. Crop Sci. 33:1111-1112. 
4. Cadle, M. M., Murray, T. D., and Jones, S. S. 1997. Identification of resistance to Pseudocercosporella herpotrichoides in Triticum monococcum. Plant Dis. 81:1181-1186.

5. Cai, X. W., Jones, S. S., and Murray, T. D. 1996. Characterization of an Agropyron elongatum chromosome conferring resistance to Cephalosporium stripe in common wheat. Genome 39:56-62.

6. Chen, Q., Conner, R. L., Laroche, A., Fedak, G., and Thomas, J. B. 1999. Genomic origins of Thinopyrum chromosomes specifying resistance to wheat streak mosaic virus and its vector, Aceria tosichella. Genome 42:289-295.

7. Cox, C. M., Murray, T. D., and Jones, S. S. 2002. Perennial wheat germ plasm lines resistant to eyespot, Cephalosporium stripe, and wheat streak mosaic. Plant Dis. 86:1043-1048.

8. de la Peña, R. C., and Murray, T. D. 1994. Identifying wheat genotypes resistant to eyespot disease with $\beta$-glucuronidase-transformed strain of Pseudocercosporella herpotrichoides. Phytopathology 84:972-977.

9. Doussinault, G., Delibes, A., Sanchez-Monge, R., and Garcia-Olmedo, F. 1983. Transfer of a dominant gene for resistance to eyespot disease from a wild grass to hexaploid wheat. Nature 303:698-700.

10. Doussinault, G., and Dosba, F. 1977. An investigation into increasing the variability for resistance to eyespot in wheat. Eyespot-variability in the subtribe Triticinae. Z. Pflanzenzuecht. 79:122-133.

11. Doussinault, G., Koller, J., Touvin, H., and Dosba, F. 1974. Problèmes posés par l'utilisation des géniteurs V.P.M.1 dans l'amélioration de l'état sanitaire du blé tendre. Ann. Amélior. Plantes 24:215-241.

12. Fedak, G., Chen, Q., Conner, R. L., Laroche, A., Comeau, A., and StPierre, C. A. 2001. Characterization of wheat-Thinopyrum partial amphiploids for resistance to barley yellow dwarf virus. Euphytica 120:373-378

13. Figliuolo, G., Jones, S. S., Murray, T. D., and Zeuli, P. L. S. 1998. Characterization of tetraploid wheat germplasm for resistance to Pseudocercosporella herpotrichoides, cause of eyespot disease. Genet. Res. Crop Evol. 45:47-56.

14. Gill, B. S., Friebe, B., and Endo, T. R. 1991. Standard karyotype and nomenclature system for description of chromosome band and structural aberrations in wheat (Triticum aestivum L.). Genome 34:830-839.

15. Groll, U., Frauenstein, K., and Hammer, K. 1985. Prüfung von AegilopsArten auf Resistenz gegen Pseudocercosporella herpotrichoides (Fron) Deighton. Kulturpflanze 33:165-172.

16. Johnson, R. 1992. Past, present and future opportunities in breeding for disease resistance, with examples from wheat. Euphytica 63:3-22.

17. Jones, S. S., Murray, T. D., and Allan, R. E. 1995. Use of alien genes for the development of disease resistance in wheat. Annu. Rev. Phytopathol. 33:429-443.

18. Keppenne, V. D., and Baenziger, S. 1990. Inheritance of the blue aleurone trait in diverse wheat crosses. Genome 33:525-529.

19. King, J. E., and Griffin, M. J. 1985. Survey of benomyl resistance in Pseudocercosporella herpotrichoides on winter wheat and barley in England and Wales in 1983. Plant Pathol. 34:272-283.

20. Knott, D. R. 1968. Translocations involving Triticum chromosomes and Agropyron chromosomes carrying rust resistance. Can. J. Genet. Cytol. 10:695-696.

21. Law, C. N., Scott, P. R., Worland, A. J., and Hollins, T. W. 1976. The inheritance of resistance to eyespot (Cercosporella herpotrichoides) in wheat. Genet. Res. 25:73-79.
22. Li, H. J., Chen, Q., Conner, R. L., Guo, B. H., Zhang, Y. M., Graf, R. J., Laroche, A., Jia, X., Liu, G. S., and Chu, C. C. 2003. Molecular characterization of a wheat-Thinopyrum ponticum partial amphiploid and its derivatives for resistance to leaf rust. Genome 46:906-913.

23. Li, H. J., Conner, R. L., Chen, Q., Li, H. Y., Laroche, A., Graf, R. J., and Kuzyk, A. D. 2004. The transfer and characterization of resistance to common root rot from Thinopyrum ponticum to wheat. Genome 47:215223.

24. Lind, V. 1999. Variation of resistance to Pseudocercosporella herpotrichoides (Fron) Deighton in wheat genotypes carrying the gene Pch-1. Plant Breed. 118:281-287.

25. Little, T. M., and Hills, F. J. 1978. Agricultural Experimentation: Design and Analysis. John Wiley \& Sons, New York.

26. Macer, R. C. F. 1966. Resistance to eyespot disease (Cercosporella herpotrichoides Fron) determined by a seedling test in some forms of Triticum, Aegilops, Secale and Hordeum. J. Agric. Sci. 67:389-396.

27. Maia, N. 1967. Obtention de blés tendres résistants au piétin-verse par croisements interspécifiques blés $\times$ Aegilops. C. R. Acad. Agric. France 53:149-154.

28. McIntosh, R. A., Dyck, P. L., and Green, G. J. 1977. Inheritance of leaf rust and stem rust resistances in wheat cultivars Agent and Agatha. Aust. J. Agric. Res. 28:37-45.

29. Murray, T. D. 1996. Resistance to benzimidazole fungicides in the cereal eyespot pathogen, Pseudocercosporella herpotrichoides, in the U.S. Pacific Northwest 1984 to 1990. Plant Dis. 80:19-23.

30. Murray, T. D., de la Peña, R. C., Yildirim, A., and Jones, S. S. 1994. A new source of resistance to Pseudocercosporella herpotrichoides, cause of eyespot disease of wheat, located on chromosome $4 \mathrm{~V}$ of Dasypyrum villosum. Plant Breed. 113:281-286.

31. Sharma, D., and Knott, D. R. 1966. The transfer of leaf rust resistance from Agropyron to Triticum by irradiation. Can. J. Genet. Cytol. 8:137143.

32. Thiele, A., Schumann, E., Peil, A., and Weber, W. E. 2002. Eyespot resistance in wheat $\times$ Aegilops kotschyi backcross lines. Plant Breed. 121:29-35

33. Wang, R. R.-C., and Wei, J. Z. 1995. Variations of two repetitive DNA sequences in several Triticeae genomes revealed by polymerase chain reaction and sequencing. Genome 38:1221-1229.

34. Wiese, M. V. 1991. Pages 47-48 in: Compendium of Wheat Diseases. 2nd ed. The American Phytopathological Society, St. Paul, MN.

35. Yildirim, A., Jones, S. S., and Murray, T. D. 1998. Mapping a gene conferring resistance to Pseudocercosporella herpotrichoides on chromosome 4V of Dasypyrum villosum in a wheat background. Genome 41:1-6.

36. Yildirim, A., Jones, S. S., Murray, T. D., Cox, T. S., and Line, R. F. 1995. Resistance to stripe rust and eyespot diseases of wheat in Triticum tauschii. Plant Dis. 79:1230-1236.

37. Yildirim, A., Jones, S. S., Murray, T. D., and Line, R. F. 2000. Evaluation of Dasypyrum villosum populations for resistance to cereal eyespot and stripe rust pathogens. Plant Dis. 84:40-44.

38. Zeven, A. C. 1991. Wheats with purple and blue grains: A review. Euphytica 56:243-258

39. Zhong, G. Y., McGuire, P. E., Qualset, C. O., and Dvorak, J. 1994. Cytological and molecular characterization of a Triticum aestivum $\times$ Lophopyrum ponticum backcross derivative resistant to barley yellow dwarf. Genome 37:876-881. 